\title{
Activating and sustaining c-Myc by depletion of miR-144/451 gene locus contributes to B-lymphomagenesis
}

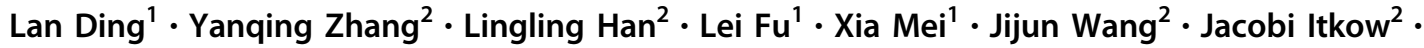 \\ Afaf Elabid Ibrahim Elabid ${ }^{2}$ Lei Pang ${ }^{2}$ D Duonan $\mathrm{Yu}^{2,3,4,5}$
}

Received: 16 June 2017 / Revised: 15 September 2017 / Accepted: 3 November 2017 / Published online: 29 December 2017

(c) The Author(s) 2018. This article is published with open access

\begin{abstract}
Hyper activity of protooncogene $c-M y c$ is one of the hallmarks of highly aggressive lymphomas. However, the mechanism of how $c-M y c$ is subjected to activation and amplification is still not well defined. In this study, we use gene knockout strategy to show that targeted depletion of a well-conserved microRNA gene locus miR-144/451 initiates tumorigenesis including B-lymphoma development in aged mice. This is due, at least in part, to the direct activation of the $c-M y c$ gene by loss of $m i R-144 / 451$ expression in hematopoietic cells. Moreover, oncoprotein c-Myc inversely regulates miR-144/451 expression by directly binding to the miR-144/451 promoter region, forming a miRNA-Myc positive feedback loop to safeguard the high level of c-Myc in B-lymphocytes. We also demonstrate that this miRNA-Myc crosstalk is disrupted in human diffuse large B-cell lymphomas with aberrant $c$-Myc expression. Therefore, our findings provide strong evidence, for the first time, that deficiency of $m i R-144 / 451$ expression may play a bona fide role in derepression of silenced c-Myc, which contributes to tumor development including B-lymphomagenesis.
\end{abstract}

\section{Introduction}

Proto-oncoprotein c-Myc (hereafter Myc) is a master nuclear factor associated with cell proliferation, survival,

Lan Ding, Yanqing Zhang, and Lingling Han contributed equally to this work.

Electronic supplementary material The online version of this article (https://doi.org/10.1038/s41388-017-0055-5) contains supplementary material, which is available to authorized users.

Duonan $\mathrm{Yu}$

dnyu@yzu.edu.cn

1 Department of Pathology, Jiangdu People's Hospital, Yangzhou University, Yangzhou, China

2 Jiangsu Key Laboratory of Experimental \& Translational Noncoding RNA Research, Yangzhou University School of Medicine, Yangzhou, Jiangsu Province, China

3 Institute of Translational Medicine, Yangzhou University School of Medicine, Yangzhou, China

4 Institute of Comparative Medicine, Yangzhou University, Yangzhou, China

5 Jiangsu Co-Innovation Center for Prevention and Control of Important Animal Infectious Disease and Zoonosis, Yangzhou, China and apoptosis [1]. Overexpression of Myc features numerous malignancies that include the highly aggressive B-cell lymphomas, such as Burkitt's lymphomas, and also a subset of diffuse large B-cell lymphomas (DLBCL) [2, 3]. Myc plays a central role in a large variety of malignancies, and therefore strategies aimed at targeting Myc have emerged as attractive cancer treatments. Studies have demonstrated that even transient shutdown of Myc is capable of inhibiting tumor growth [4]. However, conventional pharmacological approaches toward direct Myc inhibition have not proven very successful because the efficiency of direct targeting remains very low, a feature shared by many transcriptional targets. Indeed, even a genetic approach for complete shutdown of Myc, as attempted for the treatment of Mycoverexpressing murine B-cell lymphomas, has been shown to be unsatisfactory. This is because the lymphoma cells upregulate other genes involved in lymphocyte proliferation and survival, most notably interleukin 10 receptor alpha (IL10R $\alpha)$ and CD20 [5]. In addition, Myc itself is under tight transcriptional and post-transcriptional controls as are the mRNA and protein, both of which have very short halflife. Thus, inactivation of Myc, though moderately effective on its own, must include the adjuvant therapeutics that disrupt the regulatory network of Myc expression or levels in cancer cells. 
In mammalian cells, microRNA (miRNA) are a class of small noncoding RNAs, only 18-25 nucleotides in length, that are involved in gene expression by binding the $3^{\prime}$ untranslated region (UTR) of specific target mRNAs via imperfect Watson-Crick base-pairing [6]. It has been previously demonstrated by us and others, that expression of a broad spectrum of tumor-suppressive miRNAs is directly repressed by Myc [7, 8]. Conversely, some miRNAs regulate the Myc level in response to genome damaging agents [9]. This illustrates the crucial role the Myc-miRNA interaction network plays in the pathogenesis of malignant tumors [10].

miR-144/451, a bicistronic miRNA gene locus encoding miR-144 and miR-451 plays an important role in erythroid homeostasis [11-13] and is directly activated by GATA-1 [14], a transcription factor that regulates numerous aspects of erythropoiesis $[15,16]$. $m i R-144 / 451$ was considered to express abundantly and almost exclusively in erythroid cells $[14,17]$. Interestingly, growing evidence demonstrates that miR-144/451 may function as a tumor suppressive gene in some organs including the lungs [18], breast [19], and hematopoietic systems [20-24]. However, all this evidence comes from either in vitro or ex-in vivo experimental systems, and thus it is difficult to access the causal relationship of $m i R-144 / 451$ inactivation to tumor initiation. Interestingly, most lymphomas with Myc aberrations usually originate from cells with silenced Myc activity [25], suggesting that additional molecular events have disrupted the Myc regulatory network to confer the transformation of normal lymphocytes. However, the mechanism of how Myc is activated is yet to be defined. Here we use a $m i R-144 / 451$ gene knockout ( $m i R-144 / 451^{-/-}$, KO) mouse model to reveal that loss of $m i R-144 / 451$ activates Myc expression and sustains Myc level to initiate and promote Blymphomagenesis.

\section{Results}

\section{Depletion of miR-144/451 gene locus accelerates tumorigenesis in aged mice}

We have previously found that miR-451 strongly inhibits $M y c$ expression, while depletion of $m i R-144 / 451$ enhances $M y c$ expression and it's signaling in erythroblasts (unpublished data). These results suggest that $m i R-144 / 451$ is a miRNA gene locus that might function as a potential tumor suppressor. Consistent with this hypothesis, the miR-144/ $451^{-/-}$mice older than 15 months spontaneously developed different types of tumors. These tumors include B-cell lymphomas (Fig. 1a-c), acute myeloid leukemia (AML, Fig. 1d) and multiple benign liver adenomas (Fig. 1e) (Table 1). Interestingly, aged heterozygous $m i R-144 / 451^{-/+}$mice also elicited accelerated B-lymphomagenesis and AML development. This is due, at least, to the loss of heterogeneity of the miR-144/451 genomic DNA (Fig. 1f). Mice younger than 15 months rarely develop tumors (data not shown). This data firmly indicates that tumor initiation is driven by $m i R-144 / 451$ depletion. In order to reveal the potential mechanism, only the B-cell lymphoma model was investigated in the current study.

\section{miR-144/451 expression is down regulated in murine B-lymphoma cells}

Since aged $m i R-144 / 451^{-1-}$ mice spontaneously develop Blymphoma, we analyzed the miR-451 levels in different murine B-lymphoma cell lines and analyzed the primary Blymphoma cells. As shown in Fig. 2a by quantitative real time polymerase chain reaction (qRT-PCR), miR-451 is dramatically down regulated in mouse B-lymphoma cell line 38B9 [26] and Myc3 [27] compared with bone marrow (BM)-derived CD19/B220 double positive B-lymphocytes. Moreover, the miR-451 levels were also significantly lower in primary mouse B-cell lymphomas induced by constitutive Myc expression [28] (Fig. 2b). We also found significant difference of miR-144 levels between normal Blymphocytes and B-lymphoma cells (Fig. 2c, d). These results suggest that the expression of $m i R-144 / 451$ is deficient during B-lymphomagenesis.

\section{Transduction of miR-451 and miR-144 suppresses the growth of B-lymphomas}

To determine the function of $m i R-144 / 451$ expression in Bcell lymphomas, we ectopically expressed miR-451 and miR-144 in both mouse and human B-lymphoma cell lines Myc3 and Daudi, respectively. The efficiency of retrovirus (MSCV-PIG [7])-based overexpression of miR-451 and miR-144 was confirmed by qRT-PCR analyses (Fig. 3a). The cell numbers of both mouse Myc3 and human Daudi Blymphomas were significantly decreased upon transduction of miR-451 and miR-144 (Fig. 3b, c). In vivo subcutaneous tumor transplantation assay showed a markedly delayed time for developing B-lymphomas and much smaller tumors when miR-451 and miR-144 were enforcedly expressed (Fig. 3d, e). Flow cytometric analyses indicated arrested cell cycling in miR-451 and miR-144 overexpressed Myc3 lymphoma cells (Fig. 3f, g). However, miR-144 had a much less significant effect on the tumor growth and cell cycling than miR-451. Taken together, these observations demonstrate the tumor suppressor function of both miR-451 and miR-144 in B-lymphomagenesis. In light of the findings that the difference of miR-144 levels between normal B-lymphocytes and B-lymphomas was less profound, and more importantly, miR-144 alone had 
Fig. 1 miR-144/451 deletion accelerates tumorigenesis in aged mice. a Representative gloss tumor images from aged miR-144/451 ${ }^{-/-}$mice. b Histopathological image with $\mathrm{H} \& \mathrm{E}$ staining showing typical lymphoma cells. c Flow cytometric analysis showing B-cell identity of the lymphoma cells based on B220/CD19 staining. d Gloss view of a large spleen with AML and e multiple liver adenoma in aged mice. $\mathbf{f}$ Genomic DNA PCR showing loss of heterogeneity of $m i R-144 / 451^{-/+}$ genotype. M1 and M2 represent mouse 1 and mouse 2, and $\mathrm{T} 1$ and $\mathrm{T} 2$ represent tumors from $\mathrm{M} 1$ and M2, respectively
A

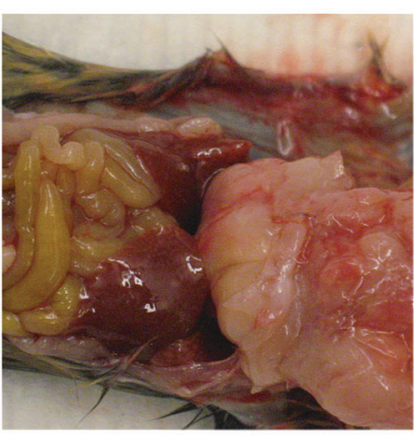

B

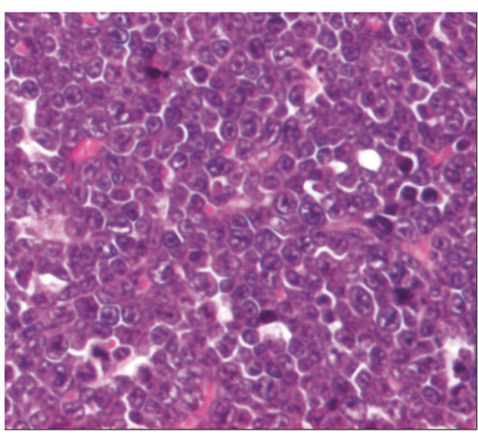

H\&E 400x

C
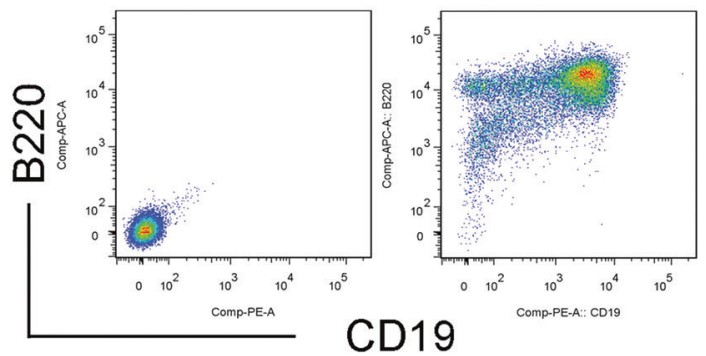

D

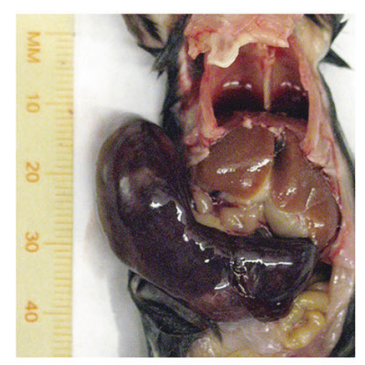

E

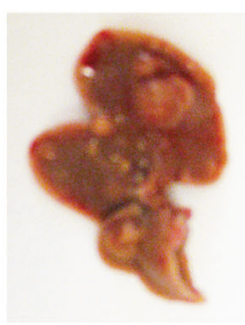

$\mathrm{F}$

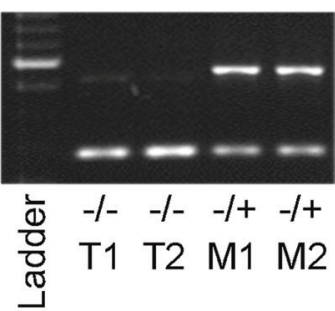

WT band

KO band
Table 1 Tumorigenesis in aged (15-18 months) $m i R-144 / 451^{-/-}$mice

\begin{tabular}{llll}
\hline Mouse genotype & $+/+$ & $+/-$ & $-/-$ \\
\hline Lymphoma/total mice (\%) & $1 / 76(1.32)$ & $6 / 75(8)$ & $8 / 85(9.41)$ \\
AML/total mice (\%) & $1 / 76(1.32)$ & $7 / 85(8.23)$ & $9 / 85(10.59)$ \\
Liver adenoma/total mice (\%) & 0 & 0 & $3 / 85(3.53)$ \\
\hline
\end{tabular}

minimal inhibition effect on tumor growth, we focused on miR-451 for further mechanism study.

\section{miR-451 directly represses Myc mRNA in B- lymphocytes}

Previous research by us and others has shown that several mRNAs are miR-451 targets including Ywhaz/14-3-3 , Cab39, and Myc [12, 20, 29]. To investigate whether miR451 directly represses Myc during B-lymphomagenesis, we searched several online databases. In silico analyses, using TargetScan, MirTarbase and Mouse Genome Informatics, showed that the sequence of miR-451 is partially complementary to a sequence within the $3^{\prime}$ UTRs of both mouse and human Myc mRNA, and is predicted as a target of miR451 (Fig. 4a, b, Supplementary Fig. 1A-B). As expected, ectopic retroviral vector-mediated expression of miR-451 in mouse 38B9 B-lymphoma cells reduced Myc protein level by approximately $27 \%$ (Fig. 4c, d). Overexpression of miR451 in human Daudi Burkitt's lymphoma cells also dramatically reduced the Myc levels (Supplementary Fig. 1CD), suggesting that human Myc is a miR-451 target. Normal bone marrow-derived B-lymphocytes express very low level of Myc, while loss of the miR-144/451 gene locus significantly elevated Myc level in bone marrow-derived Bcells (Fig. 4e, f), indicating that depletion of $m i R-144 / 451$ in B-cells sufficiently derepresses Myc expression. Moreover, the Myc levels in primary B-lymphomas developed from $m i R-144 / 451^{-1-}$ mice are comparable to those in 38B9 cells, much higher than those in yolk sac derived pre-B cell line (YS-PB11) [30] (Fig. 4g, h), confirming that the abundance of Myc is altered in tumors from miR-144/451 
Fig. $2 m i R-144 / 451$ expression is down regulated in murine $B$ lymphoma cells. a, b Quantitative real-time PCR (qRT-PCR) analysis to quantify the gene transcriptions. a miR-451 in murine B-cell lymphoma line 38B9 and Myc3. b Primary mouse B-cell lymphomas induced by constitutive Myc expression. c, d qRT-PCR analysis showing the miR-144 levels. c Murine B-lymphoma cell line 38B9 and $\mathrm{Myc} 3$. d Primary B-cell lymphomas. In all four graphs, the $\mathrm{Y}$-axis shows relative expression and the $\mathrm{miR}$ 451 or miR-144 levels from normal bone marrow-derived $\mathrm{CD} 19^{+} \mathrm{B} 220^{+} \quad$ B-lymphocytes are assigned an arbitrary relative value of 1 . (**) $p$ value $<$ 0.01 ( $t$-test). Experiments were repeated three times. Note, both miR-451 and miR-144 are dramatically down regulated in mouse B-lymphoma cells compared with normal Blymphocytes
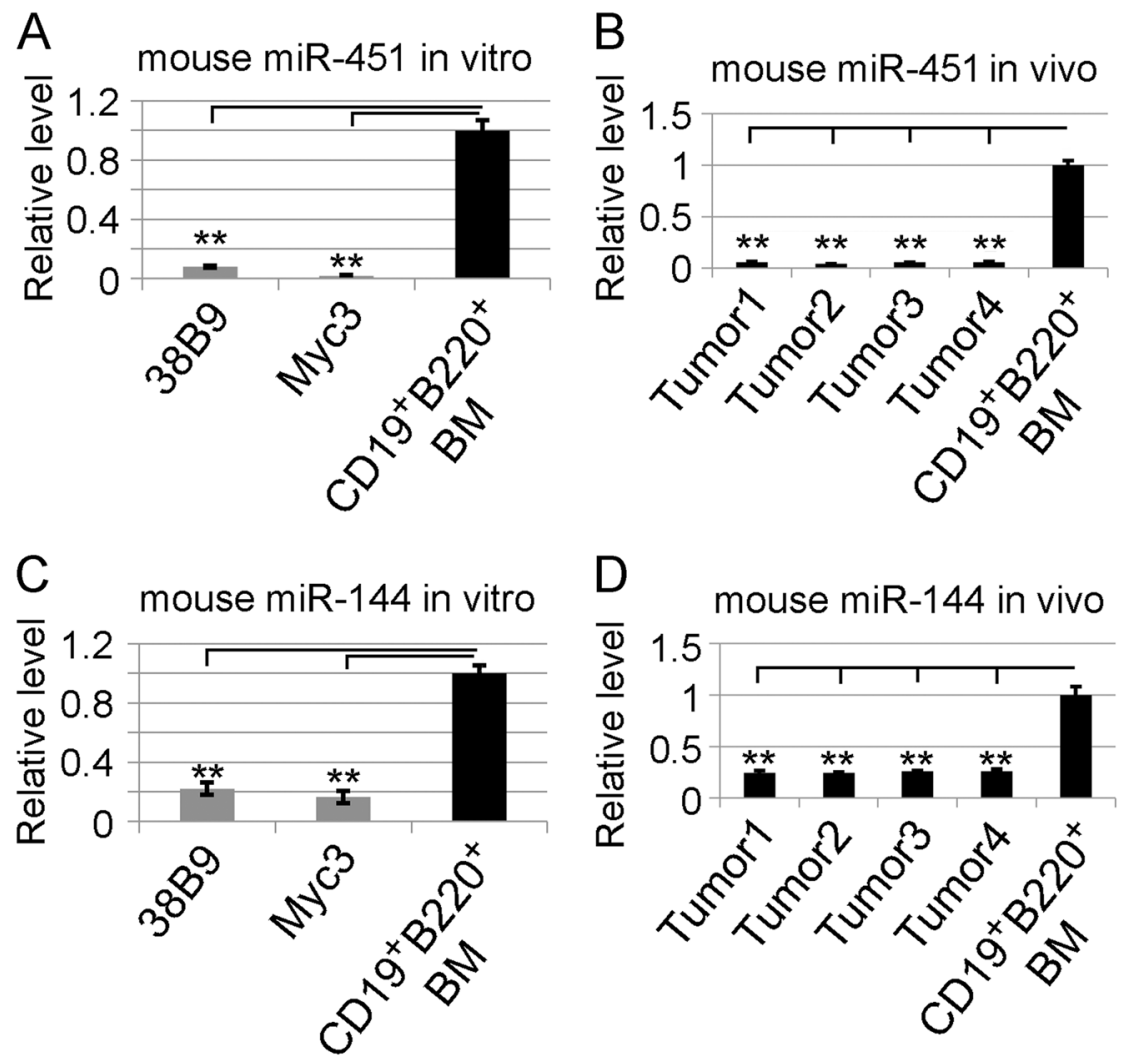

-/- mice. Though TargetScan predicts that human (not mouse) Myc mRNA is the target of miR-144, other database do not list Myc mRNA as a miR-144 target. Ectopic expression of miR-144 failed to decrease the Myc protein levels in both human Daudi cells (Supplementary Fig. 1CD) and mouse G1E cells, the erythroblasts differentiated from embryonic stem cells [31] (data not shown), demonstrating that $M y c$ mRNA is not the target of miR-144. To verify that miR-451 inhibits $M y c$ mRNA expression via direct interaction, we fused the $3^{\prime} \mathrm{UTR}$ of $M y c$ cDNA to the coding sequence of luciferase cDNA (Fig. 4i). In 38B9 cells, luciferase reporter activity was significantly inhibited after co-expression of miR-451 mimic (Fig. 4i). Three base pair replacement in the miR-451 binding site complementary to seed sequence abrogated the ability of miR451 to repress reporter activity (Fig. 4i). These results were reproduced in human Daudi cells (Supplementary Fig. 1E) and 293T cells (data not shown) using either miR-451 mimic or miR-451 expressing retroviral vector. Together, these findings verify that miR-451 inhibits $M y c$ mRNA expression directly.

\section{The activity of Myc protein and miR-451 were inversely correlated}

Recent study has shown that Myc is engaged in the suppression of miR-451 expression in AML [22], suggesting a potential feedback role of Myc and miR-144/451 in tumorigenesis. To test this assertion, we reanalyzed our published microarray dataset [7]. As a result, human P493 lymphoma cells with high Myc activity express undetectable miR-451, while cells with low Myc activity produced a pronounced level of miR-451 signal (Fig. 5a). We validated the microarray data in the same Myc-inducible P493 lymphoma system by qRT-PCR (Fig. 5b). These results provide evidence that Myc activity determines the differential expression of miR-451. To further confirm whether Myc inversely regulates miR-451 expression in B-lymphomas, we established a Myc-inducible mouse B-lymphoma model. Our B-cell lymphoma mouse model is based on an infection of p53-null bone marrow cells with retrovirus encoding a fusion gene between $M y c$ and a mutant form of estrogen receptor (MycER), requiring the presence of 4hydroxytamoxifen (4-OHT) but not estrogen for Myc activity [5, 28]. As shown in Fig. 5c, palpable tumors form and grow rapidly after continued 4-OHT treatment (Fig. 5c, myc-on), while tumor growth was dramatically reduced if 4-OHT treatment was discontinued (Fig. 5c, myc-off). However, in mice taken off 4-OHT, tumors did not undergo complete regression; instead the repressed tumors grew again in a slow pace but enlarged much more dramatically than original tumors after receiving 4-OHT again (Fig. 5c, myc-on again). qRT-PCR analyses clearly showed that Blymphoma cells with Myc activation (myc-on) expressed 

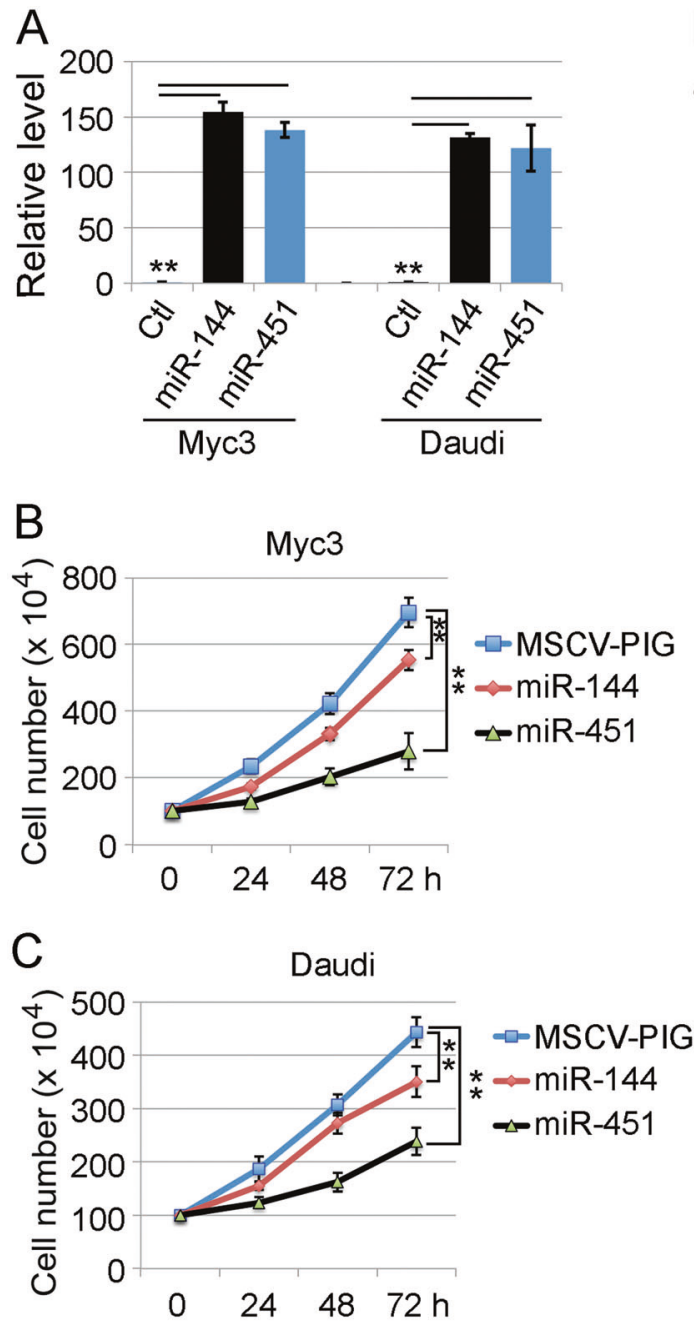

Fig. 3 Transduction of $m i R-451$ and $m i R-144$ suppresses the growth of B-lymphomas. a qRT-PCR confirming the efficiency of retrovirusbased overexpression of $m i R-451$ and $m i R-144$ in both mouse Myc3 and human Daudi B-lymphoma cells. b, $\mathbf{c}$ The cell numbers of both mouse Myc3 and human Daudi B-lymphomas in culture were counted every 24-h after transduction of $m i R-451$ and $m i R-144$ retrovirus. Representative studies from three culture dishes of each sample are shown. d, e Tumor volumes of mouse Myc3 and human Daudi B-

low level of miR-451 (Fig. 5d), and vice versa (Fig. 5e). Northern hybridization verified the PCR results (Fig. 5f, g). These studies confirm that miR-451 levels in B-lymphoma cells are inversely correlated with Myc activity.
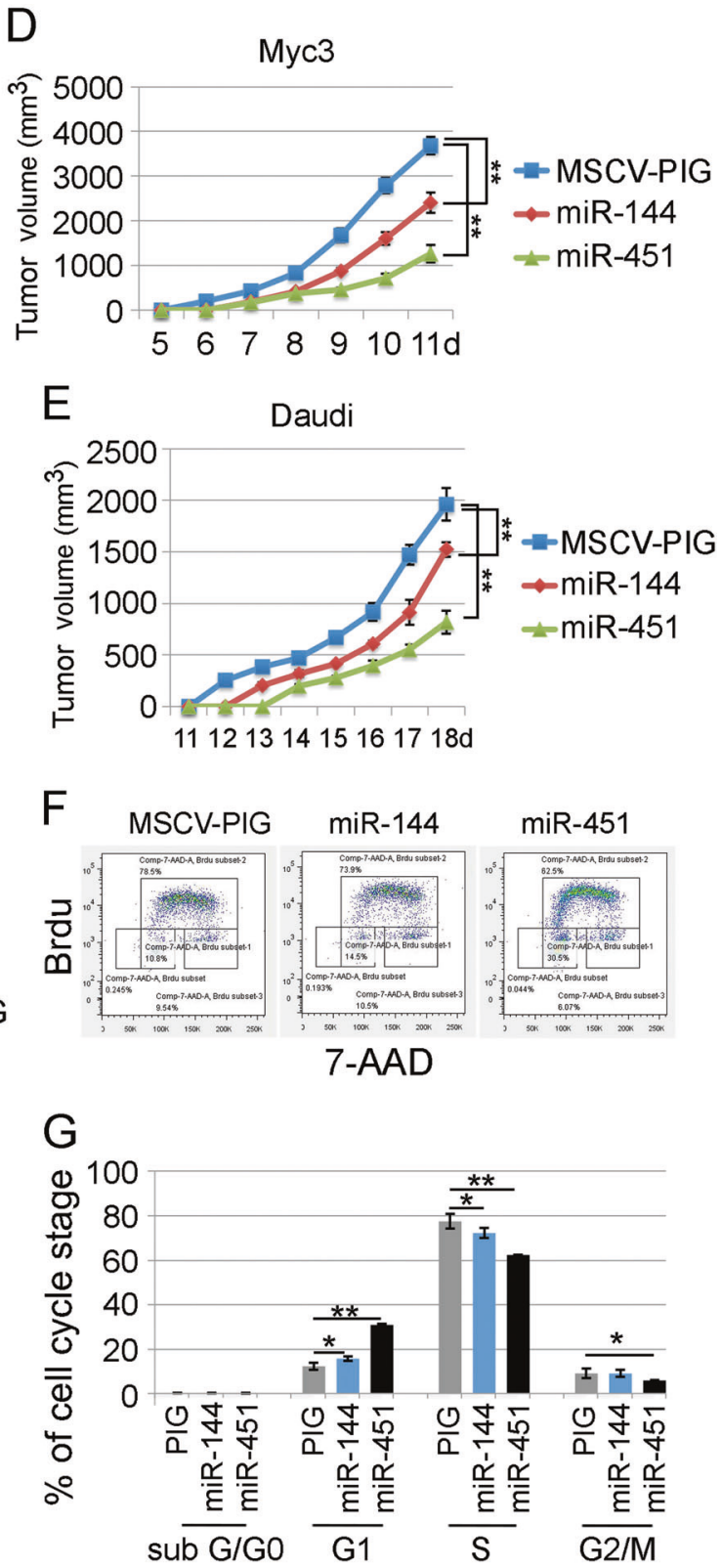

lymphomas after subcutaneous tumor transplantation with and without enforced miR-451 and miR-144 expression. Sample size $\mathrm{n}=5-6 /$ group. f Flow cytometry based BrdU incorporation assay. The Y-axis shows the relative amount of BrdU incorporated into Myc3 cells. The $\mathrm{X}$-axis shows the amount of DNA content by 7-AAD staining. $\mathrm{g}$ The percentages of sub G/G0, G1, S, and G2/M phases of Myc3 cells from BrdU assay are presented as the mean value from three different experiments. $(* *) p<0.01(t$-test $)$

\section{Myc suppresses the expression of miR-144/451 in a promoter-dependent manner}

We have previously shown that activation of Myc represses a large set of miRNAs in B-lymphoma cells via direct Myc binding in the vicinity of the transcription start sites or 
Fig. 4 miR-451 directly represses murine Myc mRNA in Blymphocytes. a Nucleotide sequence alignment showing partial complementarity between the mouse $3^{\prime} \mathrm{UTR}$ of Myc mRNA and miR-451 (from Targetscan.org). The miR-451 seed sequence recognition site in the Myc mRNA is boxed in white. b In silico analysis with Mouse Genome Informatics (MGI) showing Myc as a predicted miR-451 target. c 38B9 mouse B-lymphoma cells were transduced with retrovirus encoding miR-451 or empty vector as control. Decreased Myc protein levels in tumor cells were shown by western blotting and $\mathbf{d}$ quantitative image analysis from three separate western blots. e Increased Myc protein in bone marrow-derived miR-144/ $451^{-/-}$B-lymphocytes relative to wild-type B-cell $(+/+$, WT) controls. Representative studies from two mice of each genotype are shown. Quantitative image analysis from multiple experiments is shown in panel $\mathbf{f}$. $g$ Elevated Myc protein levels in primary B-lymphoma cells derived from $m i R-144 / 451^{-/-}$ mice relative to $38 \mathrm{~B} 9$ cells as positive control and normal mouse yolk sac-derived pre-B cells (YS-PB11) as negative control. Representative studies from two primary tumors are shown. h Quantitative analysis of Myc protein levels from primary B-lymphoma cells derived from $m i R-144 / 451^{-/}$mice. i Interaction between miR-451 mimic and Myc $3^{\prime}$ UTR in $38 \mathrm{~B} 9$ cells inhibits expression of firefly luciferase in pGL3-BS reporter system. Mutant version (mt) containing 3-bp mutation within the region complementary to miR-451 seed sequence dramatically abolished the inhibition. The bars in the right panel indicate firefly/renilla luciferase activity; with levels from reporter vector lacking the Myc 3'UTR assigned an arbitrary value of 1 . Results indicate the average of three separate experiments. (*) $p<0.05,(* *)$ $p<0.01$ ( $t$-test)

A

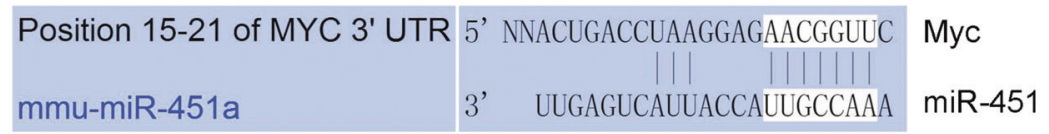

B

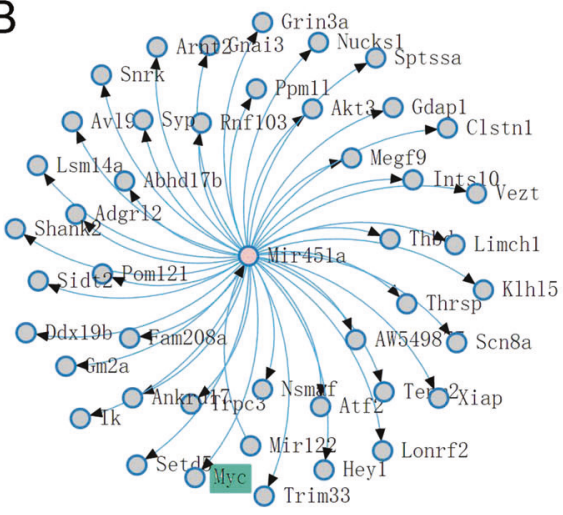

$E$

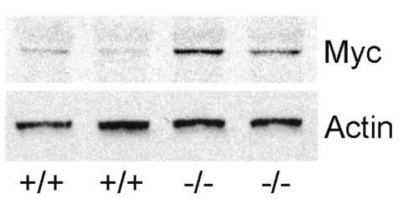

$\mathrm{H}$

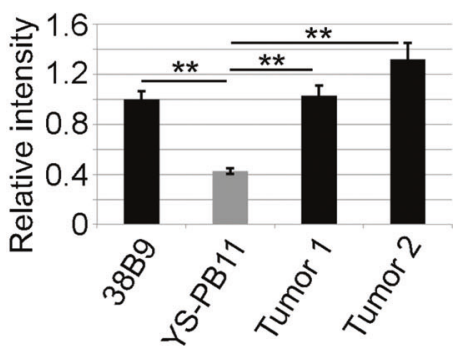

C

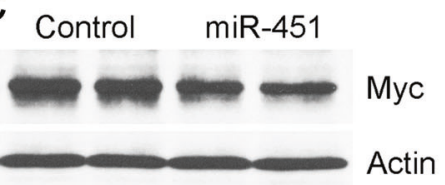

D

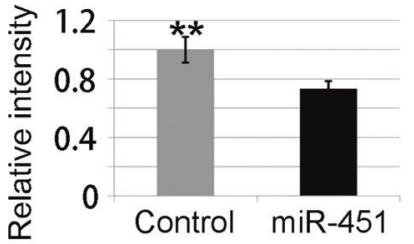

G

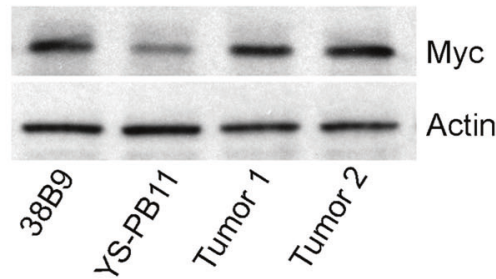

Relative Luc activity in 38B9
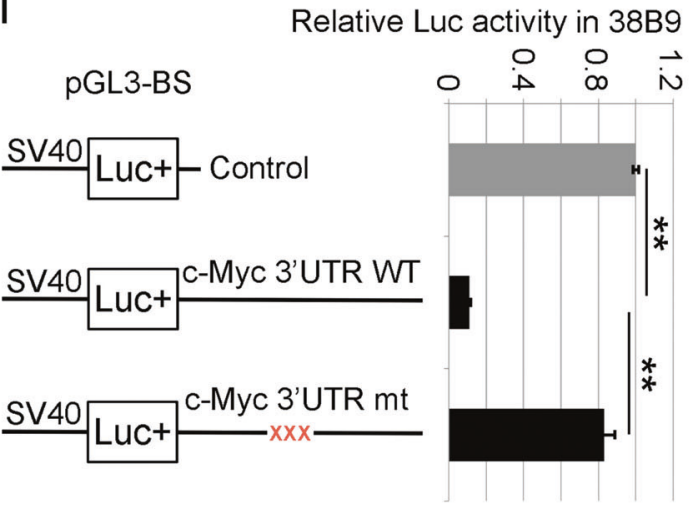
Fig. 5 The activity of Myc protein and miR-451 were inversely correlated. a MicroRNA microarray showing differential miR451 signals in human P493 lymphoma cells with or without high Myc activity. b qRT-PCR was used for validating the microarray data in the same Myc-inducible P493 lymphoma system. c A p53-null, Mycinducible mouse B-lymphoma model requiring the presence of 4-hydroxytamoxifen (4-OHT) for Myc activity. As shown in panel c, palpable tumors form and grow rapidly after continued 4-OHT treatment (myc-on), while tumor growth was dramatically reduced if 4-OHT treatment was discontinued (mycoff). However, in mice taken off 4-OHT, tumors did not undergo complete regression; instead tumors grew at a slow pace. After receiving 4-OHT again (myc-on again), tumors grew dramatically. d qRT-PCR analyses showing that B-lymphoma cells with Myc activation contained low level of miR-451, and vice versa e. f Northern hybridization was used to verify the PCR results. g Quantitative image analysis for northern blot. Results represent two separate experiments. (**) $p<0.01 \quad(t$ test)
A

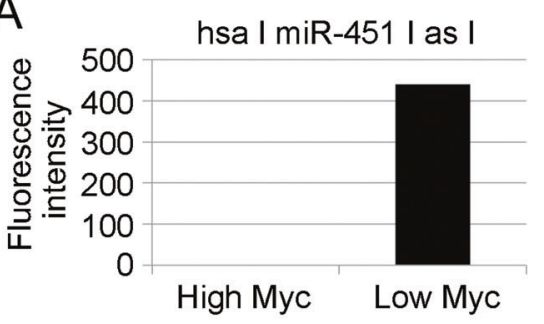

$\mathrm{B}$

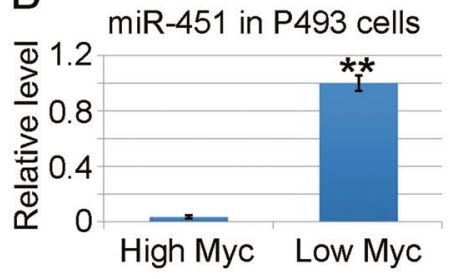

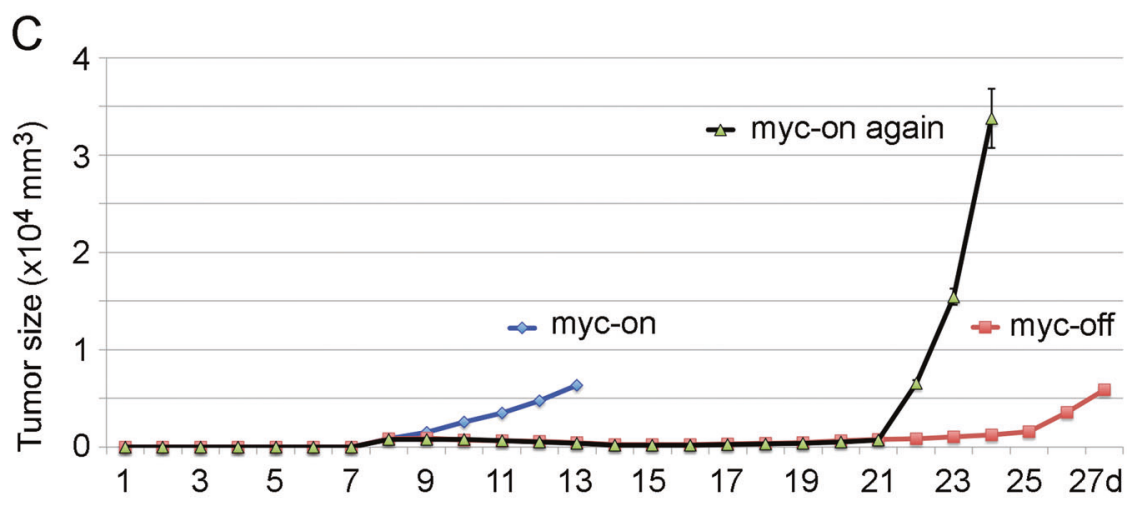

D

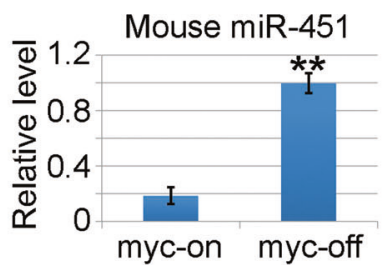

$\mathrm{F}$
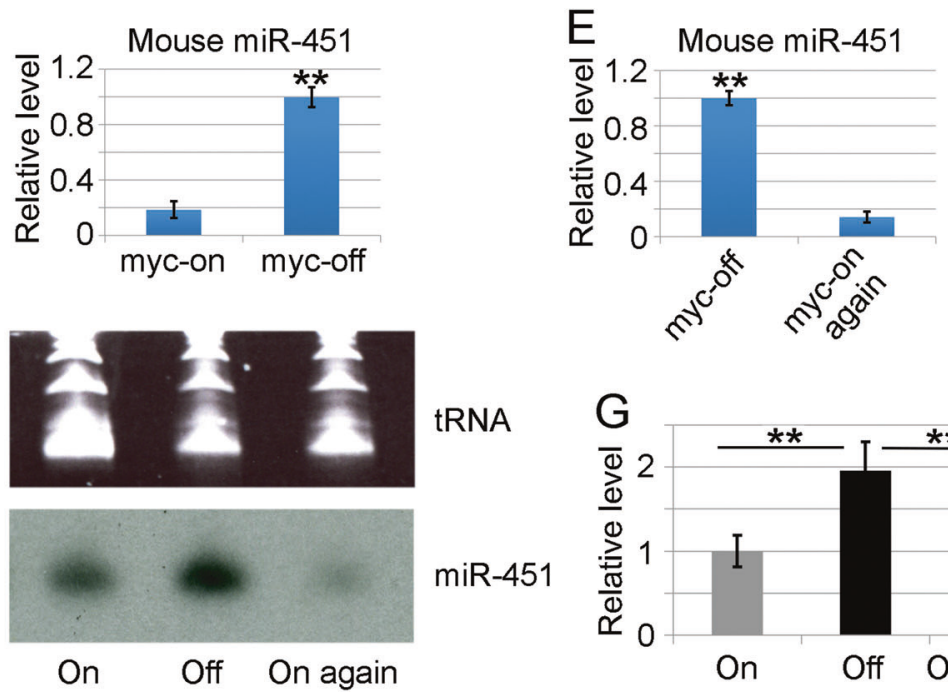

tRNA

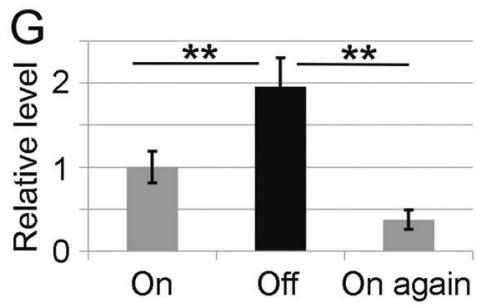

within the conserved upstream regions of the miRNA genes [7]. We therefore selected conserved regions upstream of mouse, rat, human, dog, and cow miR-144/451 pre-miRNA to design real-time PCR primers after ChIP using Myc antibody. Bioinformatics analysis using Vista software identified the potential elements that might associate with Myc protein (Fig. 6a). We observed 14-fold enrichment of a $191 \mathrm{bp}$ (BS1, -503 to -313 ) long fragment upstream of miR-144 precursor sequence in Myc-activated ChIP samples as compared with Myc-inactivated ChIP samples (Fig. $6 \mathrm{~b})$, providing strong evidence for the direct occupancy of Myc protein in miR-144/451 promoter region. No significant DNA enrichment was found nearby in less conserved (BS2) and nonconserved (NC) regions (Fig. 6b), demonstrating the specificity of Myc finding.
To further test the association of the Myc protein with the promoter of $m i R-144 / 451$ gene locus, the DNA fragments containing wild type and mutant with a deleted Myc binding site upstream of the miR-144 precursor sequence were constructed to promoter-reporter vectors (Fig. 6c). These reporters were co-transfected into YS-PB11 B-cells with migR-GFP retroviral vectors cloned with MycER fusion gene. Dual-luciferase reporter assay confirmed that the activated Myc, but not inactivated Myc, fusion protein significantly repressed the transcriptional activity of the miR-144/451 promoter, while deletion of the Myc binding site abolished the suppression of the transcription activity in YS-PB11 cells (Fig. 6c). These findings confirm that repression of $m i R-144 / 451$ observed in the high-Myc state 
Fig. 6 Myc suppresses the expression of $m i R-144 / 451$ in a promoter-dependent manner. a Bioinformatics analysis using Vista software identifying the potential Myc binding sites. The rat, human, dog, and cow genomic sequences upstream miR144 precursors were aligned with the sequence of mouse $m i R-144 / 451$ promoter region (7200 bp). b Chromatin immunoprecipitation (ChIP) using Myc antibody showing the enrichment of a 191-bp long fragment upstream of miR-144 precursor sequence when Myc is activated (Myc-on). Mycinactivated and $\mathrm{IgG}$ pulldowned ChIP samples were used as negative controls. Note, there is 14-fold difference between Myc-on and Myc-off DNA samples, suggesting the occupancy of Myc protein in miR-144/451 promoter region. Experiments were repeated three times. BS1 binding site 1, BS2 binding site 2, NC not conserved. c Dual-luciferase reporter assay in mouse yolk sac derived pre-B (YS-PB11) lymphocytes confirming the repressed transcriptional activity of $m i R-144 / 451$ promoter by Myc. Promoter-reporter vector pGL3basic (empty vector) and promoter-reporter vector pGL3enhancer (empty vector + enhancer) were used as negative and positive controls, respectively. A deletion mutant of the potential Myc binding site (mt) and Myc-inactivated wild type (WT) miR-144/451 promoter sequences were used as controls. Each sample was triplicated and the experiments were repeated twice. mt $\mathrm{P}$ mutant promoter, WT P wild type promoter. (**) $p<0.01$ ( $t$-test)

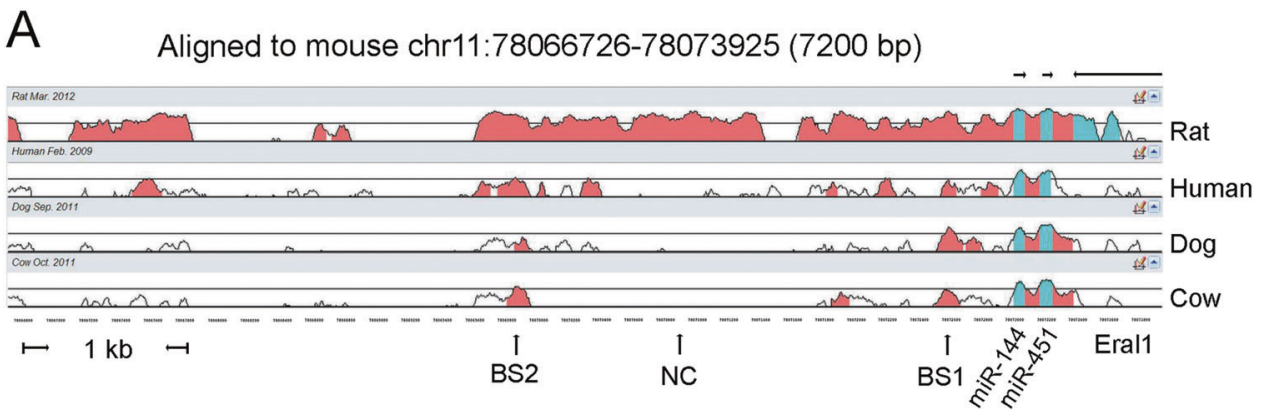

B

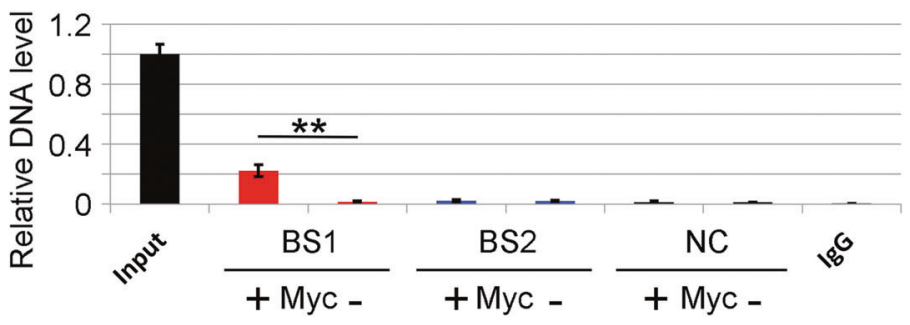

C Relative Luc activity in YS-PB11 cells

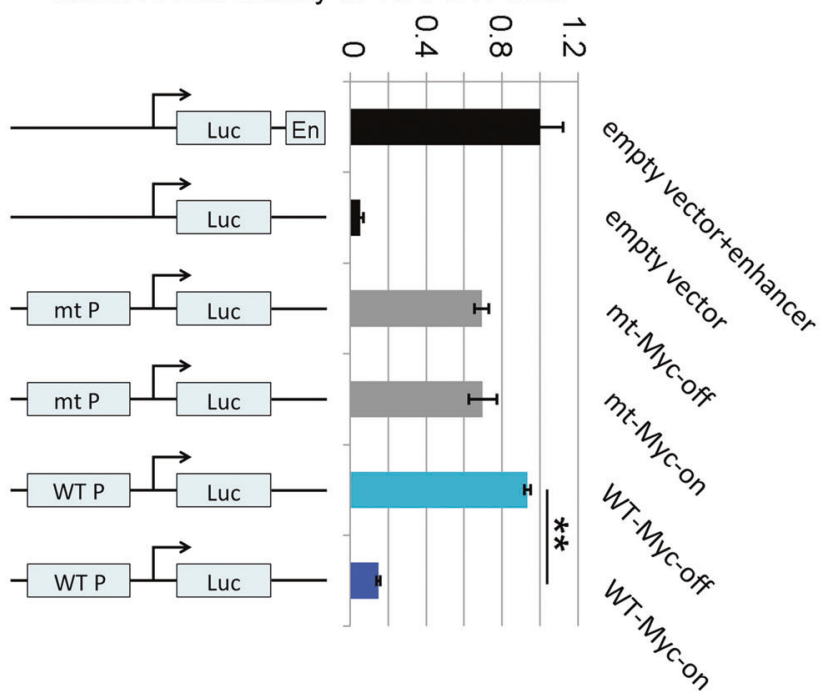

is a direct consequence of Myc binding to miR-144/451 promoter.

\section{miR-451 expression is disrupted in human B lymphoma cells with hyper Myc activity}

To investigate the correlation between miR-451 and Myc levels in human B-lymphomas, we selected seven Myc highly expressed human lymphoma cell lines Ramos, Ly91, Daudi, LCL1, Ag836, GM607, Ly47, and two Myc low expressed human lymphoma lines Jijoye and Dana to examine the miR-451 level, using human CD20 positive BM lymphocytes as control. As shown in Fig. 7a, all Myc highly expressed human B-cell lymphoma lines expressed low levels of miR-451. Jijoye and Dana, two lines previously confirmed expressing low Myc [32], expressed significantly high levels of miR-451. The miR-144 levels in these Myc highly expressed lymphomas were also significantly low compared to those in BM B-lymphocytes (data not shown). 
Fig. $7 \mathrm{miR}-451$ expression is disrupted in human B lymphoma cells with hyper Myc activity. a qRT-PCR analyzing the level of miR-451 in Myc highlyexpressed and Myc-lowexpressed human lymphoma cell lines with human CD20 positive bone marrow lymphocytes as control. The Y-axis shows the relative amount of miR-451. Representative study from three different experiments is shown. b Immunohistochemical staining of representative specimens from human diffuse large B cell lymphomas (DLBCL) patients showing the high Myc and low Myc protein levels. Inflammatory reactive lymph nodes with undetectable level of Myc as negative control (Myc-). Insets $(400 \times)$ represent tissues in red squares. c Immunohistochemical staining of CD20 showing the identity of B cell lineage. d q-RT-PCR analyzing miR-451 levels in human DLBCL samples with high and low Myc protein levels. RNA from reactive lymph nodes with undetectable Myc used as control. The Y-axis shows the relative amount of miR-451. q-RTPCR was repeated twice. e qRT-PCR analyzing miR-451 levels in subcutaneously transplanted human lymphoma P493 cells with a Myc-inducible system. The Y-axis shows the relative levels of miR-451. f Model for the interaction of miR-451-Myc: decrease of miR451 expression derepresses Myc in B-lymphocytes and high Myc level inversely inhibits miR-451 transcription. This positive feedback loop sustains the Myc level above the threshold that contributes to Blymphomagenesis. (*) $p<0.05$ $(t$-test), $(* *) p<0.01$ ( $t$-test)

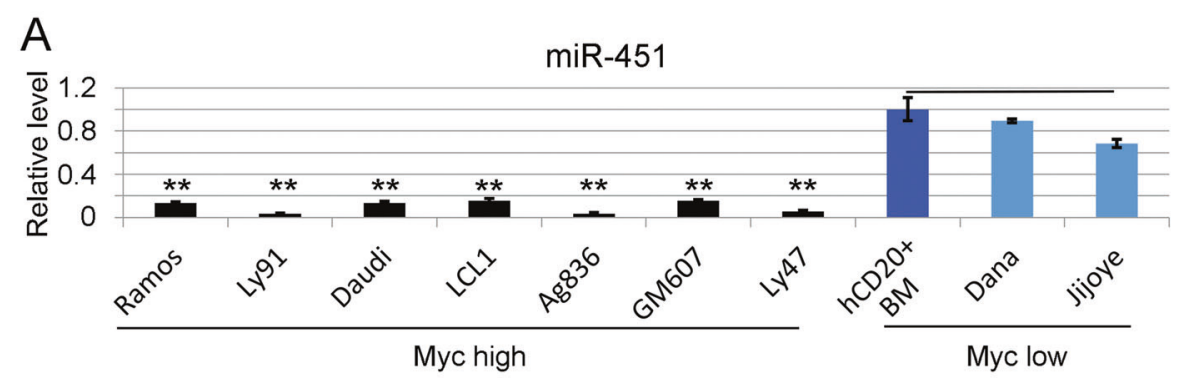

B

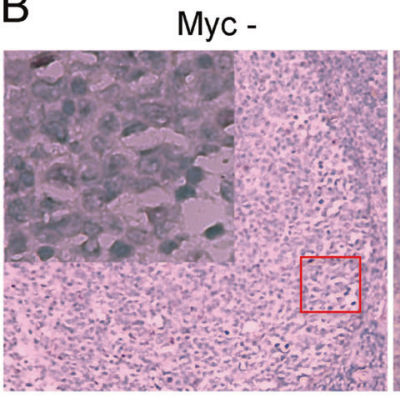

Myc low
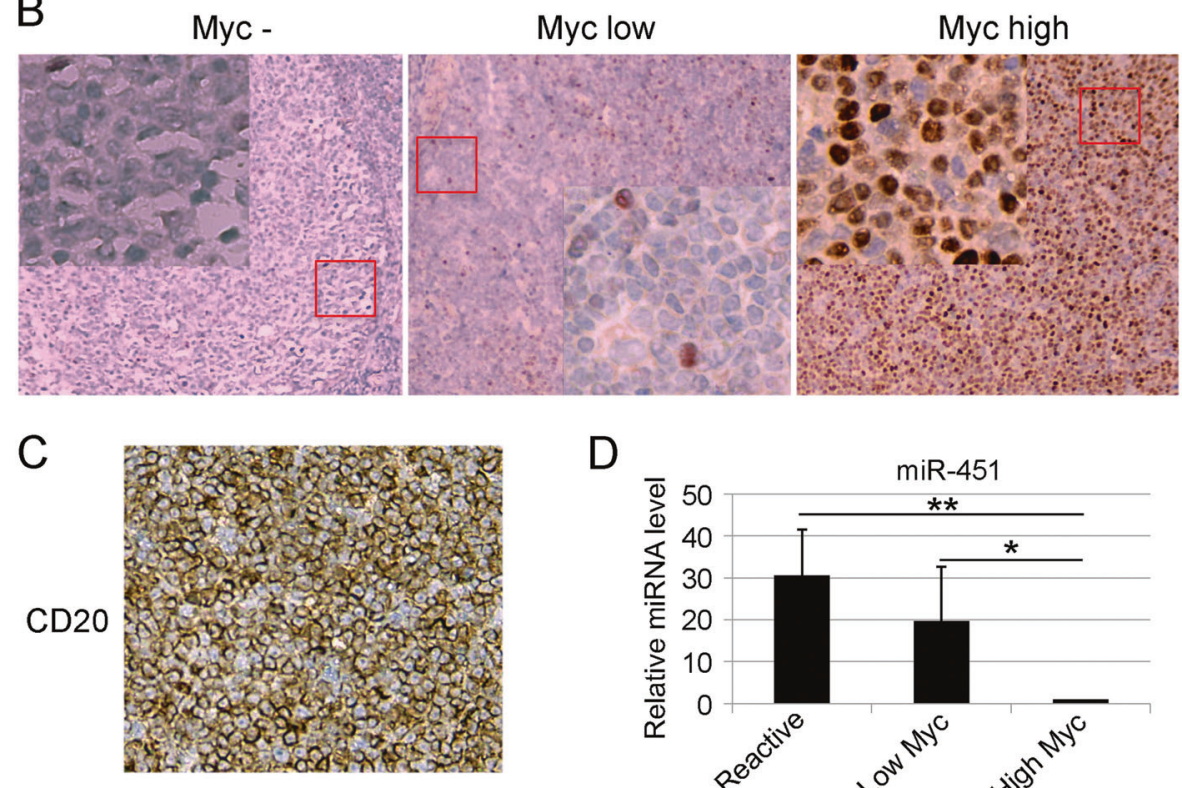

D

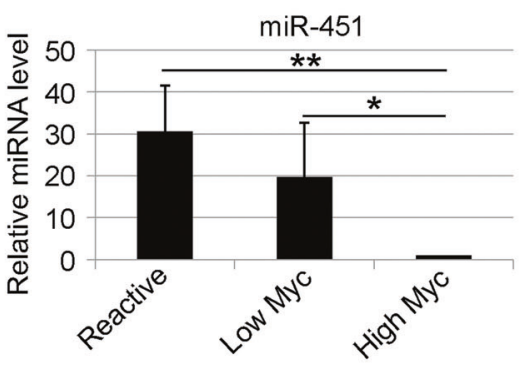

E

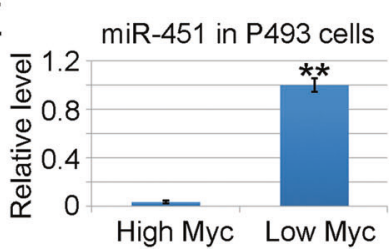

$\mathrm{F}$

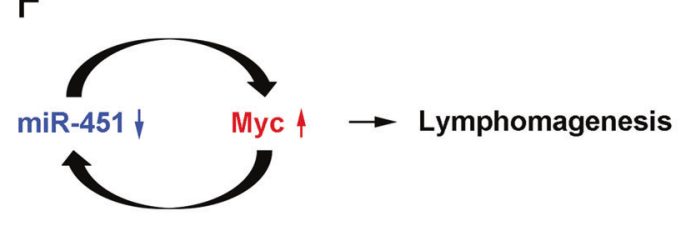

In order to investigate whether the Myc-miR-451 interaction is disrupted in human lymphoma patients, we selected 10 diffuse large B cell lymphomas (DLBCL) with high Myc and low Myc levels respectively, and another six inflammatory reactive lymph nodes with undetectable or low level of Myc as controls. The Myc level was quantified based on immunohistochemical staining (Fig. 7b). All Bcell identity was verified by CD20 staining (Fig. 7c). The results from qRT-PCR analyses were consistent with the ones from human B-lymphoma cell lines, where lymphomas with high Myc contain less miR-451 than lymphatic tissues with low Myc (Fig. 7d). Consistent results were also obtained from subcutaneously transplanted P493 human lymphoma cells with a Myc-inducible system [7], where cells with high Myc contain low level of miR-451 (Fig. 7e). Interestingly, miR-144 level in human DLBCL patients is not significantly lower than those in noncancerous control tissues (data not shown). Taken together, our findings from human lymphomas further confirm that miR-451-Myc forms a positive feedback loop and 
disruption of this functional loop contributes to lymphomagenesis (Fig. 7f).

\section{Discussion}

We have previously shown that the bicistronic gene locus $m i R-144 / 451$ is highly expressed during erythrocyte development and their expression is controlled by hematopoietic transcription factor GATA1 [14]. Moreover, miR-451 protects against erythroid oxidant stress by first repressing 14$3-3 \zeta$ and then by inhibiting nuclear translocation of antioxidant transcription factor Foxo3 [12]. Therefore, miR-451 was originally considered as an erythroid miRNA. However, recent studies have shown abnormal expression of $m i R-144 / 451$ in numerous cancers [18-24]. Additionally, ectopic expression of miR-144/451 reduces tumor growth, mainly due to their repression of oncogenic targets includ-

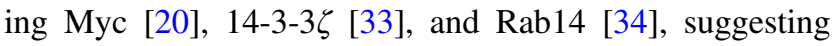
miR-144/451 as a tumor suppressive miRNA gene locus. Nonetheless, all these studies are based on the in vitro or exin vivo experiments and it is impossible to causally connect $m i R-144 / 451$ inactivation to tumor initiation. In the present study, we use a miR-144/451 gene knockout mouse model to show miR-144/451 as tumor suppressive miRNAs that inhibit the initiation of mouse lymphoma, AML and multiple liver adenomas in vivo. To the best of our knowledge, this is the first time to show loss of miR-144/451 as a driver of tumorigenesis, although the low penetrance and long latency of tumor development in miR-144/451 null mice suggests that miR-144/451 alone is unlikely a strong tumor suppressor. Speculative explanations for the low penetrance of tumorigenesis in miR-144/451 $1^{-1}$ mice include the possibility that the Myc protein levels in hematopoietic cells from a majority of the mice didn't reach the threshold level necessary for activating the oncogenic programs but certainly were enough to predispose the cells to pre-cancerous conditions. Another possibility is that a large set of human aggressive B-cell lymphomas including high-grade B-cell lymphomas (HGBL), Burkitt lymphoma, a subset of DLBCL and grey zone lymphomas with features intermediate between DLBCL and Burkitt lymphoma generally depend upon inactivation of tumor suppressors, such as $\mathrm{p} 53$, for rapid onset and high penetrance. Persistent expression of pro-proliferative or pro-survival genes such as $\mathrm{Bcl} 2$ and $\mathrm{Bcl} 6$ are also required for some aggressive B-cell lymphomas to establish the full phenotype of malignancies [35]. However, the Myc levels are still too low to destabilize the genome to generate more somatic mutations. Alternatively, miR-144/451 targets multiple mRNAs and non-coding RNAs, some of which might inhibit the tumorigenesis. The balanced molecular network could prevent the high penetrance of B-lymphomagenesis. Future study is necessary to examine whether loss of $m i R-144 / 451$ together with other mutations accelerates tumorigenesis in vivo. To this end we crossed miR-144/451 ${ }^{-/-}$mice with several other mutant animals. Our preliminary observations have shown that animals with double or triple mutations dramatically accelerate tumorigenesis with much high penetrance of tumor development. We will characterize further these mice and think this work is beyond the scope of the current study.

Myc, a helix-loop-helix leucine zipper (HLH-ZIP) protooncogenic protein, is a central transcription "hub" that directly targets about $15 \%$ of human genes [1]. However, the half-life of such an important nuclear protein is only about $15 \mathrm{~min}$, indicating the tight control of Myc level in normal cells. Although a number of mechanisms are involved in these regulations, few upstream regulators of Myc expression have been identified. Recent studies have showed that some miRNAs inactivate $\mathrm{Myc}$, and one of these miRNAs is miR-451. The Myc regulatory role of miR-451 has been suggested in several tumor models including human lung adenocarcinoma [34] and T cell acute lymphoblastic leukemia [20]. We have observed that both loss of miR-144/451 or enforced expression of miR-144/451 alter not only the Myc level but also the Myc signaling pathways in erythroblasts (unpublished data). Our finding that miR-451 directly reduces Myc levels indicates that miRNAs can target major transcription factors to suppress B-lymphomagenesis.

Myc can target as much as $15 \%$ of the human genes and the activation of target genes by Myc mainly depends on the binding of Myc to consensus "E-box" sequences in promoter regions or in the first intron of the target genes [1]. However, the mechanism of the transcriptional inactivation mediated by Myc is poorly understood. The results from current study demonstrate that Myc occupies the DNA sequence located within the promoter and transcriptionally represses miR-144/451 expression, which is consistent with our previous work that Myc widely inhibits the miRNA expression in an "E-box" independent manner [7]. In some cases, the Myc binding elements can be several $\mathrm{kb}$ and even more than $100 \mathrm{~kb}$ away from the initial transcription sites [7]. Taken together, our study confirms that the transcriptional activation and inactivation of Myc target genes depend on different binding elements of Myc protein in the regulatory regions.

Myc has been confirmed as a strong oncogenic driver in many cancers including aggressive lymphomas [3]. Our previous studies demonstrate that the growth of B-cell lymphomas in vivo is sufficiently inhibited by Myc inactivation [5]. However, a few of the tumor cells can survive and adapt to the Myc-inactivated microenvironment [5]. In the present study, we found a positive feedback loop between miR-451 and Myc. Deficient expression of $m i R$ - 
144/451 activates and sustains Myc protein level in Blymphocytes, while the activated Myc transcriptionally represses $m i R-144 / 451$ expression. More importantly, this regulatory loop is disrupted in Myc highly expressed human DLBCLs. Since Myc level is very low and tightly controlled during normal development, subtle expression change would cause substantial consequence. Although our data reveals the existence of Myc-miRNA circuit, which plays a crucial role in the initiation and development of aggressive tumors, the Myc-independent growth of B-cell lymphomas suggests other genetic or epigenetic regulatory networks are involved in the maintenance of tumor growth.

$m i R-144 / 451$ is considered as a miRNA gene locus and this is especially true in erythroid cells. We have previously shown that $m i R-144$ and $m i R-451$ are bicistronic genes whose expression is directly controlled by a "master" hematopoietic transcription factor GATA1 [14]. Interestingly, we find that Myc negatively regulates the expression of both $m i R-144$ and $m i R-451$ in mouse B lymphoma cells, but failed to detect significant down regulation of miR-144 in Myc highly expressed human DLBCLs. There are two possible explanations for this apparent discrepancy. First, any primary lymphoma tissues containing red blood cells whose miR-144/451 could contaminate the RNA samples from tumor cells could affect our ability to detect down regulation of miR-144. However, as we previously shown, high Myc level promotes vigorous tumor angiogenesis whereas low Myc level is usually linked to low tumor neovascularization [36]. In another word, DLBCLs with high Myc should contain more contaminated red blood cells and thus both miR-451 and miR-144 levels should be higher than those in DLBCLs with low Myc, but this certainly is not the case for miR-451. Second, there is an unknown mechanism that differentially controls the levels of miR-144 and miR-451 post-transcriptionally. This is evidenced by two observations: (1) miR-144 level is always lower than miR-451 level in both fetal and adult erythroid cells $[12,13]$; (2) the expression of miR-144 is ubiquitous whereas the expression of miR-451 is much more constrained in hematopoietic compartments during embryonic development [37, 38]. We strongly believe that the levels of miR-144 and miR-451 are controlled not just transcriptionally by nuclear factors but also posttranscriptionally by diverse mechanisms.

Finally, miR-451 is considered as an erythroid specific miRNA gene whose expression is mainly limited in erythroid cells. However, growing evidence has demonstrated that miR-451 can be abnormally expressed in non-erythroid cells, though at very low levels compared with expression in erythroid cells. We have recently demonstrated that a trace amount of miR-451 could have a big impact on the clearance of reactive oxidative species in red blood cells (Oncotarget, in press), suggesting that it is not necessary for at least some miRNAs to reach high levels for being functional. Our data in the present study indicates that deletion of miR-144/451 gene locus from mouse genomic DNA can transform normal B lymphocytes and myeloid lineage cells into malignancies, further confirming our finding that trace amount of miRNAs can sufficiently regulate their target genes.

In summary, we use a gene knockout mouse model to demonstrate for the first time the deficiency of $m i R-144 / 451$ expression as a weak driver of tumorigenesis in vivo. Specifically, loss of $m i R-144 / 451$ gene locus initiates cancer development from B lymphoid and myeloid lineages in aged mice. This is due, at least partially, to the direct derepression of Myc silencing in hematopoietic cells after depletion of $m i R-144 / 451$. Moreover, activated Myc further sustains its own level by transcriptional down regulation of miR-451, forming a functional miR-451-Myc feedback loop in both mouse and human lymphomas, suggesting that disruption of miRNA-Myc molecular interaction represents potential therapeutic options.

\section{Materials and methods}

\section{Animals and tumorigenesis assays}

miR-144/451 null mice lacking a 388-base-pair segment of genomic DNA containing the miR-144/451 gene locus and its genotyping were described in our published work [12]. Animals were sacrificed at the age of 12, 14, 15, and 18 months, respectively. Generation of Myc-induced and MycER-induced murine B-lymphomas has been described earlier in our laboratory [5, 27, 28]. 4-OHT (H6278, Sigma, St. Louis, MO) was dissolved in corn oil (Sigma) at the concentration of $10 \mathrm{mg} / \mathrm{mL}$ and was administrated by daily intraperitoneal injection into mice with subcutaneously transplanted cells (1 mg per mouse). Mouse Myc3 Blymphoma cells were subcutaneously injected into the syngeneic C57BL6/J mice and human Daudi cells were injected into the immunocompromised scid-beige mice. Females at the age of 8-10 weeks were used for tumor loading assay. Tumor volume was calculated using the formula $[L \times W \times(L+W) / 2]$, where $L$ is the length and $W$ is the width of the lymphoma. All animal experiments were performed with protocols approved by the Animal Care and Use Committee of the Yangzhou University School of Medicine.

\section{Cell culture}

Unless indicated specifically, all cells including Ramos, Ly91, Daudi, LCL1, Ag836, GM607, Ly47, Dana, Jijoye, YS-PB11, 38B9, Myc3 were maintained in RPMI 1640 
culture medium containing $10 \%$ fetal bovine serum (FBS) at $37^{\circ} \mathrm{C}$ in $5 \% \mathrm{CO}_{2}$. S17, a stromal cell line supporting $\mathrm{B}$ lymphopoiesis [39] was maintained in RPMI 1640 as previously shown [40]. S17 cells were irradiated at the dose of $1200 \mathrm{rad}$ and were plated with Myc3 lymphoma cells supplemented with $1 \mathrm{ng} / \mathrm{mL}$ recombinant mouse interleukin-7 (R\&D Systems, MN). Human 293T cells were cultured in DMEM with $10 \%$ of FBS. Transfection and retroviral infection were performed as described before [12]. Fortyeight hours after transfection, conditioned medium was collected and subjected to infection of tumor cells.

\section{Western blot analysis}

Whole cell protein extracts were prepared using lysis buffer with 1:500 protease inhibitor mixture (Sigma-Aldrich). Protein concentrations were analyzed using a Pierce bicinchoninic acid assay kit (Thermo Scientific, Rockford, IL) according to the manufacture's instruction. Ten microgram of protein was loaded onto $10 \%$ SDS-PAGE gel and transferred to polyvinylidene fluoride membranes (Whatman). Proteins on membrane were incubated with Myc antibody (N-262; Santa Cruz Biotechnology, Santa Cruz, CA), followed by an HRP-conjugated secondary antibody. Horseradish peroxidase-conjugated anti- $\beta$-actin antibody (clone TAC-40, Sigma-Aldrich) was used as an internal control. Western blots were visualized using SuperSignal West Pico chemiluminescent solution. Secondary antibodies were obtained from Thermo Scientific.

\section{Northern blot analysis of miR-451 and miR-144}

Blotting was done as described in our published study [12]. Briefly, $3 \mu \mathrm{g}$ of total RNA was separated in a $15 \%$ urea/ polyacrylamide/Tris-borate-EDTA gel and electrotransferred to a GeneScreen Plus Hybridization Membrane (Perkin Elmer). Membranes were then UV-cross-linked (StrataLinker; Stratagene) and hybridized overnight with ${ }^{32}$ P-labeled locked nucleic acid (LNA) probes (Exiqon). Transfer RNA (tRNA) was used as loading control.

\section{Fluorescent activated cell sorting (FACS) and BrdU assays}

Expression of cell surface molecules and BrdU incorporation assay were performed on an LSRII or an LSRFortessa instrument (BD Biosciences). Cell samples were resuspended in PBS containing $0.1 \%$ BSA (FACS buffer) and stained with fluorescence-labeled antibodies for $30 \mathrm{~min}$ on ice. Data were analyzed with FlowJo software (TreeStar). Antibodies against mouse CD45R (B220, Cat\# 553079) and CD19 (Cat\# 553786) were purchased from BD Biosciences. The BrdU assay kit (Cat\# 559619) was purchased from BD
Biosciences and cell cycle analyses were performed according to manufacturer's instructions.

\section{qRT-PCR analysis}

Total RNA was extracted with the Trizol reagent (Invitrogen). Total RNA from Paraffin-embedded tissues was isolated using RNAprep pure FFPE Kit (Cat \# DP439, TianGen, China) according to the manufacturer's instruction. DLBCL was confirmed and selected by pathologists. qRT-PCR was performed by investigators not knowing the histopathological and immunophenotypic characteristics of the human lymphoma specimen. All-in-One ${ }^{\mathrm{TM}}$ miRNA qRT-PCR Detection kit (GeneCopoeia, Rockville, MD, USA) was used to quantify miRNA levels according to the manufacturer's instructions. The small RNA U6 was used as internal control for miRNA detection. qRT-PCR was performed on an ABI 7500 real-time PCR system (Applied Biosystems). Relative miRNA level was calculated using the $\delta \mathrm{Ct}$ method. All reactions were conducted in triplicate. Forward primers for miR-451, miR-144, and U6 were 5'AAA CCG TTA CCA TTA CTG AGT T-3', 5'-TAC AGT ATA GAT GAT GTA CT-3' and 5'-CGC TTC GGC AGC ACA TAT AC-3', respectively, and the Universal Adaptor PCR Primer (GeneCopoeia) was used as the reverse primer.

\section{Chromatin immunoprecipitation (ChIP) assay}

ChIP was performed on primary MycER B-lymphoma cells in the presence or absence of 4-OHT and was done as described in our published work [7] using anti-Myc (N262, Santa Cruz Biotechnology) antibody for MycER fusion protein. Immunoprecipitated DNA fragments were purified and analyzed by qRT-PCR using primers for miR-451 promoter and control DNA. Three pairs of primers were used for ChIP analysis. ChIP-BS1: Forward (F), 5'-GCA GGC AAA GAG TTA AGA AGC-3'; Reverse (R), 5'-CCA CTC CAA GGA CTG CTT AC-3'. ChIP-BS2: F, 5'-CAC AGG CTC TCT GGC TGG TA-3'; R, 5'-CAC AGA CAG CCA AGC TCC TT-3'. ChIP-NC: F, 5'-TGT CAG CCT GAG CAA CCC AA-3'; R, 5'-TAC TGA GTG CAA GGG CTG CA-3'.

\section{Dual luciferase reporter assay}

A 152 bp Myc 3' UTR fragment containing a potential miR451 binding site was cloned into the $\mathrm{Xba} \mathrm{I} / \mathrm{EcoR} \mathrm{I}$ restriction sites of the modified pGL3-BS luciferase reporter vector [12]. Mutation in the Myc 3'UTR was introduced by oligonucleotide-directed PCR mutagenesis as described previously [12]. 293T cells seeded in 24-well plate were transfected with $1 \mu \mathrm{g}$ of pGL3-BS reporters, $0.01 \mu \mathrm{g}$ of Renilla luciferase vector and $1 \mu \mathrm{g}$ MSCV-miR-451-PIG 
retroviral vector using Lipofectamine 2000 (Invitrogen). 38B9 B-lymphoma cells were co-transfected with $1 \mu \mathrm{g}$ of pGL3-BS reporters, $0.01 \mu \mathrm{g}$ of Renilla vector, and $10 \mathrm{nM}$ miR-451 mimic using HiPerfect Transfection Reagent in 24-well plate according to manufacture's instructions (Qiagen). Alexa Fluor 488 siRNA was used to monitor transfection efficiency. Both miR-451 mimic (Syn-mmu-miR451a miScript miRNA Mimic, cat\# 219600) and Alexa Fluor 488 siRNA (AllStars Neg. siRNA AF 488, Cat\# 1027284) were purchased from Qiagen. Detection of luciferase activity was performed on Veritas Microplate Luminometer (Promega) $24 \mathrm{~h}$ after transfection using the Dual-Luciferase Reporter (DLR) Assay kit (Promega). Primers for Myc 3'UTR cloning were used as following: F, 5'ACA CTC TAG AAA CTG ACC TAA CTC GAG GAG$3^{\prime}$; R, 5'-ACA CGA ATT CAT GGC TGA AGC TTA CAG TCC-3'.

For the measurement of miR-144/451 promoter activity, a $372 \mathrm{bp}$ wild type promoter sequence was cloned and a deletion mutant lacking of $191 \mathrm{bp}$ mouse miR-144/451 DNA fragment in the promoter region was synthesized and engineered into pGL3-basic reporter vector. One microgram of such constructs together with $1 \mu \mathrm{g}$ migR-MycER-GFP retroviral vector [5] and $0.01 \mu \mathrm{g}$ Renilla reporter were cotransfected into mouse yolk sac derived pre-B (YS-PB11) lymphocytes using HiPerfect Transfection Reagent (Qiagen). pGL3-enhancer vector was used as positive control. Cells were harvested $36 \mathrm{~h}$ post-transfection and luciferase activity was measured with DLR system according to the manufacturer's protocol. All transfection assays were carried out in triplicate and experiments were repeated three times. Following primers were used for cloning of wild type promoter region: F, 5'-ACA CCT CGA GTT CCC AGC ACA GGA AAC TAA G-3'; R, 5'-ACA CAG ATC TGT AGA CCT TAG CTT CCT TCT C-3'.

\section{Histology and immunohistochemical staining}

Paraffin-embedded lymphoid tissues from either inflammatory reaction or DLBCL patients were obtained from the Department of Pathology at the Jiangdu People's Hospital of Yangzhou University, and the related studies were approved by the Ethic Committees of the Institutional Review Board of the Yangzhou University School of Medicine. All tissues were fixed in $4 \%$ formalin and embedded in paraffin. Hematoxylin and eosin (H\&E) staining was carried out on 4 micron sections.

For Myc and CD20 staining, paraffin-embedded tissue slides were deparaffinized in xylene and rehydrated in graded alcohol. Nonspecific binding sites were blocked using 5\% normal rabbit serum for $20 \mathrm{~min}$. The slides were probed with $100 \mu$ ldiluted (1:40) primary antibodies (Myc, N262, Santa Cruz, CA, and CD20, L26, Invitrogen) for $2 \mathrm{~h}$.
Biotin labeled secondary antibody was applied for $60 \mathrm{~min}$ followed by incubation with the appropriate solutions from the avidin-biotin complex method Kit (PK-4004, Vector Laboratories) for $45 \mathrm{~min}$. The Myc or CD20 were visualized with Dako DAB Chromagen (K3465, DAKO) and the tissues were counterstained with Hematoxylin QS (H3404, Vector Laboratories).

\section{Statistical analysis}

Statistical analyses were performed using SPSS 11.0 software. If not further specified in the manuscript, all experiments were performed at least three times and data were presented as mean \pm standard deviation. Two-tailed Student's $t$-test was used for comparisons of two independent groups and one-way ANOVA was used to determine the difference among three groups or more. $P<0.05$ was considered statistically significant.

\section{URLS}

UCSC Genome Browser, http://genome.ucsc.edu/;

Vista software package, http://genome.lbl.gov/vista/ index.shtml;

MicroRNA database Targetscan, http://www.targetscan. org/vert_71/;

MicroRNA database miRbase, http://www.mirbase.org/;

Mouse Genome Informatics, http://www.informatics.jax. org/;

MirTarbase, http://mirtarbase.mbc.nctu.edu.tw/php/sea rch.php.

Acknowledgements The authors would like to thank Dr. Mitch Weiss (St. Jude Children's Research Hospital), Dr. Andrei ThomasTikhonenko (University of Pennsylvania/Children's Hospital of Philadelphia), and their laboratories for the technical supports. We are grateful to Dr. Robert Auerbach (University of Wisconsin-Madison) for YS-PB11 cells and Dr. Kenneth Dorshkind (University of California) for S17 stromal cells. We are also grateful to Yuanjun Yu for language editing. This work is supported by the National Natural Science Foundation of China (Grant No. 81670186 and 81470277, D. Y.; 81302041, Y.Z.), the Priority Academic Program Development of Jiangsu Higher Education Institution (Veterinary Medicine, D.Y.), the Natural Science Foundation of Jiangsu Province of China (15KJA320007, D.Y.; BK20130454, Y.Z.) and grant from the Ministry of Finance of China for "Biology \& Medical Science Innovation Team" program (D.Y.).

Author contributions L.D., Y.Z., and D.Y. designed the study; L.D., Y.Z., L.H., L.F., X.M., J.W., J.I., A.E.I.E., and L.P. performed the experiments; D.Y., L.D., and Y.Z. analyzed the data; D.Y. wrote the manuscript. All authors have reviewed the manuscript.

\section{Compliance with ethical standards}

Conflict of interest The authors declare that they have no competing interests. 
Open Access This article is licensed under a Creative Commons Attribution-NonCommercial-ShareAlike 4.0 International License, which permits any non-commercial use, sharing, adaptation, distribution and reproduction in any medium or format, as long as you give appropriate credit to the original author(s) and the source, provide a link to the Creative Commons license, and indicate if changes were made. If you remix, transform, or build upon this article or a part thereof, you must distribute your contributions under the same license as the original. The images or other third party material in this article are included in the article's Creative Commons license, unless indicated otherwise in a credit line to the material. If material is not included in the article's Creative Commons license and your intended use is not permitted by statutory regulation or exceeds the permitted use, you will need to obtain permission directly from the copyright holder. To view a copy of this license, visit http://creativecommons. org/licenses/by-nc-sa/4.0/.

\section{References}

1. Dang CV. MYC on the path to cancer. Cell. 2012;149:22-35.

2. Korać P, Dotlić S, Matulić M, Zajc Petranović M, Dominis M. Role of MYC in B cell lymphomagenesis. Genes. 2017;8:pii: E115.

3. Ott G, Rosenwald A, Campo E, Understanding MYC-driven aggressive B-cell lymphomas: pathogenesis and classification. Blood. 2013;122:3884-91.

4. Jain M, Arvanitis C, Chu K, Dewey W, Leonhardt E, Trinh M, et al. Sustained loss of a neoplastic phenotype by brief inactivation of MYC. Science 2002;297:102-4.

5. Yu D, Dews M, Park A, Tobias JW, Thomas-Tikhonenko A. Inactivation of Myc in two-hit B-lymphomas causes dormancy with elevated levels of interleukin-10 receptor and CD20: implications for adjuvant therapies. Cancer Res 2005;65:5454-61.

6. Bartel DP. MicroRNAs: genomics, biogenesis, mechanism, and function. Cell 2004;116:281-97.

7. Chang TC, Yu D, Lee YS, Wentzel EA, Arking DE, West KM, et al. Widespread microRNA repression by Myc contributes to tumorigenesis. Nat Genet. 2008;40:43-50.

8. Zhang X, Zhao X, Fiskus W, Lin J, Lwin T, Rao R, et al. Coordinated silencing of MYC-mediated miR-29 by HDAC 3 and EZH2 as a therapeutic target of histone modification in aggressive B-Cell lymphomas. Cancer Cell 2012;22:506-23.

9. Cannell IG, Kong YW, Johnston SJ, Chen ML, Collins HM, Dobbyn HC, et al. p38 MAPK/MK2-mediated induction of miR34c following DNA damage prevents Myc-dependent DNA replication. Proc Natl Acad Sci Usa 2010;107:5375-80.

10. Tao JC, Zhao XH, Tao JG. c-MYC-miRNA circuitry: a central regulator of aggressive B-cell malignancies. Cell Cycle. 2014;13:191-8.

11. Patrick DM, Zhang CC, Tao Y, Yao H, Qi X, Schwartz RJ, et al. Defective erythroid differentiation in miR-451 mutant mice mediated by 14-3-3zeta. Genes Dev 2010;24:1614-9.

12. Yu D, Dos Santos CO, Zhao G, Jiang J, Amigo JD, Khandros E, et al. miR-451 protects against erythroid oxidant stress by repressing 14-3-3zeta. Genes Dev 2010;24:1620-33.

13. Rasmussen KD, Simmini S, Abreu-Goodger C, Bartonicek N, Di Giacomo M, Bilbao-Cortes D, et al. The miR-144/451 locus is required for erythroid homeostasis. J Exp Med 2010;207:1351-8.

14. Dore LC, Amigo JD, Dos Santos CO, Zhang Z, Gai X, Tobias JW, et al. A GATA-1-regulated microRNA locus essential for erythropoiesis. Proc Natl Acad Sci Usa 2008;105:3333-8.

15. Yu M, Riva L, Xie H, Schindler Y, Moran TB, Cheng Y, et al. Insights into GATA-1-mediated gene activation versus repression via genome-wide chromatin occupancy analysis. Mol Cell 2009;36:682-95.
16. Cheng Y, Wu W, Kumar SA, Yu D, Deng W, Tripic T, et al. Erythroid GATA1 function revealed by genome-wide analysis of transcription factor occupancy, histone modifications, and mRNA expression. Genome Res 2009;19:2172-84.

17. Zhang L, Flygare J, Wong P, Lim B, Lodish HF. miR-191 regulates mouse erythroblast enucleation by down-regulating Riok3 and Mxi1. Genes Dev 2011;25:119-24.

18. Wang R, Chen DQ, Huang JY, Zhang K, Feng B, Pan BZ, et al. Acquisition of radioresistance in docetaxel-resistant human lung adenocarcinoma cells is linked with dysregulation of miR-451/cMyc-survivin/rad-51 signaling. Oncotarget 2014;5:6113-29.

19. Bergamaschi A, Katzenellenbogen BS. Tamoxifen downregulation of miR-451 increases 14-3-3 $\zeta$ and promotes breast cancer cell survival and endocrine resistance. Oncogene 2012;31:39-47.

20. Li X, Sanda T, Look AT, Novina CD, von Boehmer H. Repression of tumor suppressor miR-451 is essential for NOTCH1induced oncogenesis in T-ALL. J Exp Med 2011;208:663-75.

21. Du J, Liu S, He J, Liu X, Qu Y, Yan W, et al. MicroRNA-451 regulates stemness of side population cells via PI3K/Akt/mTOR signaling pathway in multiple myeloma. Oncotarget 2015;6:14993-5007.

22. Su R, Gong JN, Chen MT, Song L, Shen C, Zhang XH, et al. cMyc suppresses miR-451-YWTAZ/AKT axis via recruiting HDAC3 in acute myeloidleukemia. Oncotarget 2016;7: 77430-43.

23. Wang $\mathrm{H}$, Wang A, Hu Z, Xu X, Liu Z, Wang Z. A critical role of miR-144 in diffuse large B-cell lymphoma proliferation and invasion. Cancer Immunol Res 2016;4:337-44.

24. Soltani I, Douzi K, Gharbi H, Benhassine I, Teber M, Amouri H, et al. Downregulation of miR-451 in Tunisian chronic myeloid leukemia patients: potential implication in imatinib resistance. Hematology 2017;22:201-7.

25. Karube K, Campo E. MYC alterations in diffuse large B-cell lymphomas. Semin Hematol 2015;52:97-106.

26. Alt F, Rosenberg N, Lewis S, Thomas E, Baltimore D. Organization and reorganization of immunoglobulin genes in A-MuLVtransformed cells: rearrangement of heavy but not light chain genes. Cell 1981;27:381-90.

27. Yu D, Allman D, Goldschmidt MH, Atchison ML, Monroe JG, Thomas-Tikhonenko A. Oscillation between B-lymphoid and myeloid lineages in Myc-induced hematopoietic tumors following spontaneous silencing/reactivation of the EBF/Pax5 pathway. Blood 2003;101:1950-5.

28. Yu D, Thomas-Tikhonenko A. A non-transgenic mouse model for B-cell lymphoma: in vivo infection of p53-null bone marrow progenitors by a Myc retrovirus is sufficient for tumorigenesis. Oncogene 2002;21:1922-7.

29. Godlewski J, Nowicki MO, Bronisz A, Nuovo G, Palatini J, De Lay $\mathrm{M}$, et al. MicroRNA-451 regulates LKB1/AMPK signaling and allows adaptation to metabolic stress in glioma cells. Mol Cell 2010;37:620-32.

30. Lu LS, Auerbach R, Characterization and differentiation of an early murine yolk sac-derived IL-7-independent pre-pro-B cell line. J Immunol 1998;161:1284-91.

31. Gregory T, Yu C, Ma A, Orkin SH, Blobel GA, Weiss MJ. GATA-1 and erythropoietin cooperate to promote erythroid cell survival by regulating bcl-xL expression. Blood 1999;94:87-96.

32. Perez-Chacon G, de los Rios C, Zapata JM. Indole-3-carbinol induces cMYC and IAP-family downmodulation and promotes apoptosis of Epstein-Barr virus (EBV)-positive but not of EBVnegative Burkitt's lymphoma cell lines. Pharmacol Res 2014;89:46-56.

33. Li Y, Wang J, Dai X, Zhou Z, Liu J, Zhang Y, et al. miR-451 regulates FoxO3 nuclear accumulation through Ywhaz in human colorectal cancer. Am J Transl Res 2015;7:2775-85. 
34. Wang R, Wang ZX, Yang JS, Pan X, De W, Chen LB. MicroRNA-451 functions as a tumor suppressor in human nonsmall cell lung cancer by targeting ras-related protein 14 (RAB14). Oncogene 2011;30:2644-58.

35. Ott G. Aggressive B-cell lymphomas in the update of the 4th edition of the World Health Organization classification of haematopoietic and lymphatic tissues: refinements of the classification, new entities and genetic findings. Br J Haematol 2017. doi: https://doi.org/10.1111/bjh.14744.

36. Dews M, Homayouni A, Yu D, Murphy D, Sevignani C, Wentzel E, et al. Augmentation of tumor angiogenesis by a Myc-activated microRNA cluster. Nat Genet 2006;38: 1060-5.
37. Kloosterman WP, Wienholds E, de Bruijn E, Kauppinen S, Plasterk RH. In situ detection of miRNAs in animal embryos using LNA-modified oligonucleotide probes. Nat Methods 2006;3:27-9.

38. Diez-Roux G, Banfi S, Sultan M, Geffers L, Anand S, Rozado D, et al. A high-resolution anatomical atlas of the transcriptome in the mouse embryo. PLoS Biol. 2011;9:e1000582

39. Collins LS, Dorshkind K. A stromal cell line from myeloid longterm bone marrow cultures can support myelopoiesis and B lymphopoiesis. J Immunol 1987;138:1082-7.

40. Yu L, Zhao Y, Gu X, Wang J, Pang L, Zhang Y, et al. Dual effect of LPS on murine myeloid leukemia cells: pro-proliferation and anti-proliferation. Exp Cell Res 2016;344:210-8. 